\title{
DEFESA DA CONCORRÊNCIA NOS PORTOS
}

Gesner Oliveira

Professor Adjunto do Departamento de Economia da EAESP/FGV e Presidente do CADE.

E-mail: gesner@eaesp.fgvsp.br

César Mattos

Mestre em Economia pela PUC/RJ e

Assessor do CADE.

RESUMO: Este artigo procura avaliar o sistema portuário brasileiro à luz da questão concorrencial. A despeito de o governo ter obtido sucesso no estímulo à concorrência entre portos após 1990, o mesmo não ocorreu para os vários serviços de operação portuária. Como a concorrência entre portos no Brasil é imperfeita, dadas as grandes distâncias envolvidas, a falta de concorrência dos serviços nos portos tende a aumentar os preços cobrados acima dos níveis competitivos, incrementando o chamado "Custo Brasil". Há uma série de fatores que influenciam a falta de concorrência nos serviços portuários, sendo que o principal objetivo do artigo é avaliar as fontes possíveis de barreiras à entrada que podem bloquear a concorrência nos serviços portuários do país.

ABSTRACT: This article studies the Brazilian port system in the light of competition issues. Since the competition between ports in Brazil is imperfect, this lack of competition inside the ports raises the operation prices above competitive levels, increasing the so-called "Brazil Cost". The main target of this article is to evaluate the sources of entry barriers that could block competition inside the ports in Brazil.

PALAVRAS-CHAVE: concorrência, portos, Órgão Gestor da Mão-de-Obra (OGMO), Conselho de Autoridade Portuária (CAP), teminais privativos.

KEY WORDS: competition, ports, Port Management Council (CAP), port labour council (OGMO), private port terminals. 


\section{INTRODUÇÃO}

O objetivo deste texto é avaliar a questão portuária no Brasil na ótica da concorrência a partir do texto da Lei 8.630/93 e dos problemas atuais com a sua implementação. Além da competição entre portos, a formação do custo final de transporte para o usuário dono da carga dependerá do grau efetivo de concorrência nos mercados constituídos pelos diferentes agentes econômicos dentro do porto. Assim, o problema do custo portuário é abordado inicialmente por meio da análise da concorrência em cada segmento da operação portuária, desde o frete, passando pela operação de movimentação da carga, até a saída do porto. No final, procurar-se-á estabelecer uma visão de conjunto das relações entre os agentes e suas implicações para a estratégia de redução do Custo Brasil no porto.

A seção II aponta os aspectos mais gerais da questão portuária e os limites da ótica concorrencial. A seção III apresenta a questão da concorrência interportos versus intraporto no contexto da reforma do início da década de 90 e o papel das CIAs Docas.

O Conselho de Autoridade Portuária (CAP) é tratado na seção IV, apresentando-se as possíveis implicações de sua constituição do ponto de vista do usuário. A idéia do CAP como órgão regulador permeia essa análise. A concorrência no contexto da operação portuária é avaliada na seção V. A seção VI aborda a questão correlata da concorrência na oferta de mãode-obra. Dois pontos principais merecem destaque nessa questão: o Órgão Gestor da Mãode-Obra (OGMO) e o serviço de praticagem.

Nas seções VII e VIII, são discutidas as questões dos terminais privativos e da concorrência entre as empresas de navegação, respectivamente. A seção IX procura demonstrar as interrelações entre os agentes econômicos que operam no porto, suas implicações para a concorrência e, por conseguinte, para a formação do custo portuário.

Uma seção conclusiva contém um sumário dos principais pontos e recomendações de política. Estas últimas, se implementadas, poderiam contribuir para eventual aperfeiçoamento regulatório no setor. Nesse sentido, o CADE deveria analisar a oportunidade de emitir recomendação na direção apontada em seu papel de advogado da concorrência. Independentemente de alteração no atual marco regulatório, a relevância da questão portuária e a freqüência de imperfeição dos mercados analisados justificam redobrada atenção e rigor na aplicação da Lei 8.884/94 nesta área.

\section{A formação do custo final de transporte para o usuário dono de carga dependerá do grau efetivo de concorrência nos mercados constituídos pelos diferentes agentes econômicos dentro do porto.}

\section{MODERNIZAÇÃO PORTUÁRIA, CONCORRÊNCIA E O CADE: ASPECTOS GERAIS}

A Lei 8.630/93 constituiu avanço, embora ainda apresente ambigüidades no que tange à questão concorrencial. Se, por um lado, vários de seus dispositivos estimulam a concorrência das operações portuárias, conferindo maior margem de manobra aos usuários, a flexibilidade existente pode gerar lacunas que, na prática, possibilitam a manutenção de privilégios por meio de barreiras à entrada nas operações portuárias. Cumpre avaliar em que medida tais limitações podem gerar prejuízos à concorrência sem quaisquer ganhos de eficiência na operação portuária.

O momento atual da economia brasileira, no qual coexistem o grande esforço do governo federal de implementar a Lei $8.630 / 93$ por meio do GEMPO (Grupo Executivo para a Modernização dos Portos), a consolidação dos processos de estabilização de preços e de abertura econômica e a emergência de novo aparato regulatório, em que o CADE ocupa papel de destaque, parece especialmente oportuno para uma maior atuação do órgão na questão portuária.

Nesse contexto, pode-se dizer que o vigor da concorrência nos portos afeta a concorrência em praticamente todos os setores tradeables 
1. Para uma discussão sobre o Custo Brasil ver OLIVEIRA, G. J., MATTOS, C. C. A. "Redução do Custo Brasil: uma agenda para 1996." Secretaria de Política Econômica/Ministério da Fazenda, fev. 1996 (mimeo)

2. Em 1995 , cerca de $25,9 \%$ do valor $F 0 B$ das exportações e $29 \%$ do valor CIF das importaçōes foram realizadas por Santos.

3. A importância da pré-qualificação no jogo concorrencial dentro do porto será melhor avaliada no próximo item.

4. LIMA, E. T., VELASCO, L. M. 0 sistema portuário brasileiro. Revista do BNDES. dez. 1996.

5. GEMPO (Grupo Executivo para Modernização dos Portos). Programa Integrado de Modernização Portuária. Diário Oficial, n.220, 12/11/1996.

6. Ver relatório da FIPE, Custo Santos, análise do mercado e das cadeias logísticas, de julho de 1996. da economia. De fato, o grau de influência da abertura econômica sobre a contestabilidade dos mercados internos naqueles setores apresenta forte conexão com os custos (e, por conseguinte, com a concorrência) nos portos. Afinal, a grande massa de importações entra no país pelo porto, fazendo com que a não-consecução dos objetivos concorrenciais nesse setor possa prejudicar parte dos ganhos de bem-estar almejados com a abertura econômica. Isso sem falar nos impactos sobre a competitividade das exportações brasileiras. Não há, de fato, tema no qual convirjam de forma tão plena, objetivos de política pública de defender a concorrência e reduzir o Custo Brasil. ${ }^{1}$

\section{ADMINISTRAÇÃO DO PORTO, OPERAÇÃO PORTUÁRIA E CONCORRÉNCIA}

O Quadro 1 resume a evolução do sistema de administração portuária no Brasil.

Antes de 1990, seria difícil conceber tanto a concorrência entre os portos como no interior dos próprios portos, considerando que havia apenas um administrador, o próprio governo, pela Portobrás.

A idéia de descentralização permeia o sistema pós-1990, com a extinção da Portobrás, e promove a concorrência entre portos, apesar da responsabilidade única do Ministério dos Transportes, da continuidade da administração pelas CIAs Docas e de uma natural concentração de cargas em Santos, ${ }^{2}$ reflexo da própria concentração da atividade econômica no país.

Por outro lado, apesar da importância do estímulo da concorrência interportos, há que se reconhecer os seus limites para reduzir os custos portuários e aumentar a eficiência das operações. Características estruturais, associadas principalmente ao diferencial de custo de transporte terrestre entre um porto e outro, tornam a existência de concorrência interportos condição necessária, mas não suficiente, para atingir aqueles objetivos. É lícito supor que, em vários casos, certos portos apresentam características de monopólio natural, tornando implausível uma concorrência acirrada dentro de uma determinada área geográfica. Ou seja, o "mercado de portos" apresenta imperfeições, tornando desejável uma atenção especial ao fomento da concorrência intraporto. Isso inclui a concorrência entre terminais, operadores, trabalhadores, entre outros aspectos.

Um passo importante que está sendo dado nesse sentido é o do programa de desestatização do governo federal no setor portuário. No entanto, não está claro o quanto esse processo deverá avançar no sentido da desestatização da própria administração portuária. Apesar de a Lei 8.630/93 ser perfeitamente consistente com a desestatização das CIAs Docas, também não determina que tal processo seja obrigatoriamente seguido. Nesse sentido, o legislador preferiu uma opção de maior flexibilidade, deixando que a maturidade institucional de cada porto defina qual o melhor modelo de administração portuária a seguir.

De qualquer forma, em um regime de transição, a Lei concebeu no Parágrafo $3^{\circ}$ do Artigo 90 que a administração do porto (hoje as CIAs Docas) seria considerada pré-qualifica$\mathrm{da}^{3}$ como operadora portuária.

Segundo Lima \& Velasco, ${ }^{4}$ a nova Lei eliminou a exclusividade das CIAs Docas nas operações de capatazia (movimentação no cais através de funcionários próprios das CIAs Docas). No entanto, conforme acentua o GEMPO," "na maioria dos portos, o setor público continua exercendo a exclusividade na prestação dos serviços de capatazia", o que é frontalmente contrário ao disposto na Lei, prejudicando uma importante fonte de concorrência intraporto consoante aos objetivos do programa de desestatização. As conseqüências desse atraso no repasse de várias funções das CIAs Docas em Santos, por exemplo, estão retratadas no estudo da FIPE, ${ }^{6}$ no qual todas as

Quadro 1 - Sistema portuário pré e pós-Portobrás

\begin{tabular}{|l|l|}
\hline Slstema pré-1990 & Sistema pós-1990 \\
\hline $\begin{array}{l}\text { Mals de } 30 \text { portos públicos administrados } \\
\text { pelas CIAs Docas, diretamente pela } \\
\begin{array}{l}\text { Portobrás, por empresas sob administraçāo } \\
\text { prlvada ou por concessionárias estaduais. }\end{array}\end{array}$ & $\begin{array}{l}\text { Desativação da Portobrás, passando o } \\
\text { Ministério dos Transportes a ser diretamente } \\
\text { responsável pela política portuária por meio } \\
\text { de oito ClAs Docas federais, cinco estaduais } \\
\text { e uma privada. }\end{array}$ \\
\hline
\end{tabular}


empresas com terminais privativos próprios apresentam uma reclamação em comum: a baixa eficiência da CODESP.

\section{A ECONOMIA POLÍTICA DO CONSELHO DE AUTORIDADE PORTUÁRIA}

A instância máxima de deliberação criada pela Lei 8.630/93, no âmbito de cada porto, foi o Conselho de Autoridade Portuária (CAP). O CAP é uma espécie de "órgão regulador" de cada porto, constituído por quatro blocos, cada um com um voto: poder público, operadores portuários, trabalhadores e usuários.

O legislador estabeleceu explicitamente como função do CAP, no Inciso VI do Artigo 30, "zelar pelo cumprimento das normas de defesa da concorrência". É elucidativo neste ponto um exercício sobre a lógica de funcionamento do CAP. Em cada um dos blocos acima há pelos menos dois representantes de grupos diferentes, que devem entrar em consenso para definir um voto único dentro do bloco. $O$ voto de decisão do CAP, no caso de empate (2`2), ficaria a cargo do bloco do poder público. Este é constituído por um representante do governo federal, um do estado e outro do município-sede do porto.

Cabe avaliar o quanto os representantes do município e mesmo do estado terão seus interesses mais identificados com os interesses dos operadores portuários e trabalhadores (que tenderiam a reduzir a concorrência nas operações dentro do porto) ${ }^{7}$ ou com os dos usuários (que tenderiam aumentar a concorrência). A depender disso, os usuários podem, no máximo, empatar. No entanto, nessa configuração de $2 ` 2$, o voto de qualidade é exercido pelo presidente do CAP, que será o representante do governo federal (Artigo 31, Inciso I, Alínea A), que, em tese, favoreceria os usuários.

\section{CONCORRÊNCIA INTRAPORTO: O OPERADOR PORTUÁRIO}

\section{Pré-qualificação do operador portuário}

O Artigo $9^{\circ}$ define que "a pré-qualificação do operador portuário será efetuada junto à administração do Porto, na forma de norma publicada pelo CAP com exigências claras e objetivas". Além disso, o Inciso III do Parágrafo $1^{\circ}$ do Artigo 33 atribui à adminis- tração do porto a pré-qualificação dos operadores portuários. Ou seja, o CAP normatiza e a administração do porto aplica a norma na préqualificação.

Para avaliar como se dá a concorrência entre operadores portuários é fundamental saber como são as regras de entrada nesse mercado. A existência de barreiras institucionais depende das normas exaradas pelo CAP e da aplicação das mesmas pela administração dos portos. Tais normas serão mais ou menos restritivas em relação à entrada de operadores portuários a depender dos resultados das votações dentro do CAP e da boa vontade de implementação das mesmas pelas CIAs Docas. Segundo Lima \& Velasco, " "uma reforma portuária, com incentivo à concorrência entre operadores portuários, é um excelente programa de incentivo às exportações".

É útil uma digressão para avaliar a lógica de funcionamento do órgão responsável pelas regras de pré-qualificação: o CAP. É natural que o bloco dos operadores portuários, por ter como representantes agentes já qualificados, tenda a buscar regras mais restritivas, maximizando as barreiras à entrada para os que ainda não estão qualificados. Observe-se que, em tese, os representantes dos trabalhadores podem entrar em acordo com os representantes dos operadores em troca de melhores condições de remuneração. Lembre-se de que no Artigo 29 define-se que "a remuneração, $a$ definição das funções, a composição dos ternos e as demais condições do trabalho portuário avulso serão objeto de negociação entre as entidades representativas dos trabalhadores portuários avulsos e dos operadores portuários". Ou seja, se os operadores portuários puderem repassar para os usuários custos maiores derivados de uma negociação frouxa da remuneração, fixação dos ternos etc., pode se tornar vantajoso para aqueles dois blocos entrarem em acordo em detrimento do bloco dos usuários. Observe-se que 50\% do bloco dos trabalhadores é constituído por avulsos (categoria mais ativa politicamente) e $50 \%$ pelos demais trabalhadores.

Do ponto de vista das CIAs Docas, devese analisar a disposição de cada uma em préqualificar operadores portuários que, em última análise, a estarão substituindo na transição para um regime de operações portuárias mais privatizado. ${ }^{9}$

Em suma, o regime concorrencial da operação portuária depende tanto das normas que
7. Na seção sobre pré-qualificação do operador portuário, discute-se majs detalhadamente a lógica do possivel conluio trabalhador-operador.

\section{LIMA, E. T., VELASCO, L. M. Op. cit.}

9. Lembrar que as CIAs Docas já foram consideradas na Lei como pré-qualificadas no Parágrafo $3^{\circ}$ do Artigo $\%^{\circ}$. 
têm sido expedidas pelos CAPs para a pré-qualificação como da implementação das mesmas pelas administrações portuárias.

O processo concorrencial dos operadores portuários pode ser limitado, ademais, por razões estruturais. Isso porque é necessário um mínimo de capital fixo (portrainers, guindastes etc.) do operador portuário para que este possa estar apto a operar adequadamente. A verificação de elevados custos fixos tende a gerar economias de escala no curto prazo, limitando, naturalmente, o número de entrantes.

Além disso, uma infinidade de operadores compromete a capacidade de administração do porto e amplia o problema de assimetria de informação do usuário em face da qualidade dos serviços dos operadores. Assim, o dispositivo da pré-qualificação, apesar de constituir uma possível barreira à entrada burocrática, pode apresentar também uma justificativa do ponto de vista da eficiência que deve ser ponderada.

Além disso, é fundamental que as normas exaradas pelo CAP (o que deve estar no regulamento do porto, segundo o Artigo 10 da Lei) privilegiem, ao máximo, a liberdade de escolha do operador portuário pelo usuário e as regras específicas para os terminais privativos. Assim, juntamente com a questão das eventuais barreiras burocráticas à entrada para a préqualificação de operadores, é importante avaliar qual a liberdade de escolha dos usuários em relação aos operadores que estejam préqualificados em cada porto.

Um ponto fundamental a observar é que a Lei 8.630/93 não impede que seja concedida exclusividade de exploração de um porto inteiro ou mesmo de terminais, áreas ou serviços. A Lei foi sábia em não introduzir restrições, tendo em vista a heterogeneidade de tamanho dos portos brasileiros. No entanto, torna-se importante atenção especial das autoridades de defesa da concorrência para que exclusividades para operadores portuários injustificadas não sejam efetuadas.

\section{Dispensa de operador portuário}

O Parágrafo $1^{\circ}$ do Artigo $8^{\circ}$ torna dispensável a intervenção de operadores portuários nas operações portuárias em certas circunstâncias, especialmente quando a operação, "por seus métodos de manipulação, suas características de automação ou mecanização, não requeiram a utilização de mão-de-obra ou pos- pria tripulação das embarcações" (Inciso I do

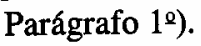

Trata-se de um dispositivo importante por permitir ao usuário fazer uma movimentação portuária mais barata que a ofertada pelos operadores locais. Isso inibiria a ação concertada dos operadores portuários locais no sentido de aumentar o custo da operação. $O$ Parágrafo $2^{\circ}$ do Artigo $8^{0}$ apresenta maior alcance ainda ao permitir que o interessado, entendendo como necessária a utilização de mão-de-obra complementar, a requisite ao Órgão Gestor da Mãode-Obra (OGMO). Há três problemas potenciais a serem avaliados na prática:

1. Não está claro quem define se uma determinada operação se enquadra nas características definidas no Inciso I do Parágrafo $1^{\mathrm{o}}$, os próprios usuários, os armadores, a administração do porto ou o CAP. A flexibilidade conferida pela Lei depende de tal definição.

2. Não está assegurado o grau de liberdade do interessado em utilizar a mão-de-obra complementar.

3. Há uma natural assimetria de informação da grande parte dos usuários em relação à operação portuária vis-à-vis o operador portuário. Nesse aspecto, é importante realçar o papel do operador portuário na redução do custo de transação para o usuário, o qual evita a necessidade de lidar com as várias fases do complexo processo de embarque e desembarque no porto, que in- clui aduana, armazenamento, contratação de mão-de-obra na estiva, capatazia, conferência etc. É difícil, em vários casos, vislumbrar a possibilidade da dispensa do operador. De qualquer forma, é importante avaliar com que frequiência os usuários têm se utilizado desse dispositivo e a que custo.

\section{CONCORRÊNCIA INTRAPORTO: A MÃO-DE-OBRA PORTUÁRIA}

\section{Implantação do OGMO e concorrência}

Anteriormente (e ainda hoje) a contratação da mão-de-obra nos portos era feita diretamente no sindicato. Além disso, conforme Lima \& Velasco, ${ }^{10}$ "as condições de remuneração, a definição das funções e as demais condições de trabalho eram objeto de determinação federal, suprimindo qualquer tipo de concorrência entre trabalhadores ou grupo de trabalhadores pelos serviços nos portos". O sindicato 
também costumava privilegiar grupos específicos de trabalhadores em detrimento de outros na atribuição dos serviços.

A Lei 8.630/93 transferiu essa prerrogativa para os OGMOs. O OGMO deve ser constituído pelos operadores portuários (caput Artigo 18), constituído de um Conselho de Supervisão (CS) e uma diretoria executiva. $\mathrm{O} C S$ deve ser composto por representantes dos operadores portuários, dos usuários e dos trabalhadores. A diretoria executiva é dos operadores portuários. Nesse caso, as condições de trabalho (remuneração, definição das funções etc.) passam a ser negociadas coletivamente com os operadores portuários, estimulando a concorrência entre portos, ${ }^{11}$ mas não intraporto. Os operadores portuários também possuem a liberdade de requisitar ao OGMO os trabalhadores que desejarem, fomentando, em tese, a concorrência entre estes pela maior eficiência. No entanto, nada impede que os critérios de eficiência sejam menos privilegiados, dada a possibilidade de colusão entre operadores e trabalhadores em detrimento dos usuários, dificultando a concorrência intraporto. ${ }^{12}$

É importante ressaltar que os Incisos IV e $\mathrm{V}$ do Artigo 18 determinam que compete ao OGMO "selecionar e registrar o trabalhador portuário avulso" cuja oferta será restrita pelo "número de vagas, a forma e a periodicidade para acesso ao registro do trabalhador portuário". Ou seja, substituiu-se o sindicato pelo OGMO no gerenciamento da mão-de-obra portuária, transferindo-se o monopólio da mão-de-obra de uma entidade (o sindicato) para outra (o OGMO). Além disso, o OGMO é dominado pelo operador portuário, que, como vimos acima, não obrigatoriamente, terá interesses convergentes com os usuários no que tange a custos de movimentação. De qualquer forma, o sistema ainda é superior para o usuário em relação ao anterior, em que este não tinha qualquer representação e o sindicato monopolizava o gerenciamento da mão-de-obra.

Segundo o GEMPO, ${ }^{13}$ "os OGMOs já estão criados em todos os portos organizados" (o que foi uma conquista que contou com fundamental impulso do GEMPO após três anos de total inércia na implementação dos mesmos), além de "quase todos já terem assumido o processamento do pagamento dos trabalhadores". No entanto, a administração do fornecimento de mão-de-obra avulsa ainda está em fase de implantação, reconhecendo o

GEMPO ser ainda incipiente o estágio de organização da maioria dos OGMOs criados.

Um reflexo claro disso ainda se observa nas regras atuais de alocação de mão-de-obra em Santos. Conforme a FIPE," "na descarga de um navio de containers com dois guindastes operando, são alocadas, em terra, duas equipes de trabalhadores, dois ternos por guindaste mais dois feitores, mais dois anotadores e mais dois mestres, além de um contra-mestre geral'. Além disso, são alocados quatro trabalhadores na peação ou desapeação, atingindo-se 17 trabalhadores. De acordo com algumas estimativas, seria necessário somente $40 \%$ da mãode-obra atualmente utilizada no trabalho de embarque e desembarque.

\section{Pode-se dizer que o vigor da concorrência nos portos afeta a concorrência em praticamente todos os setores tradeables da economia.}

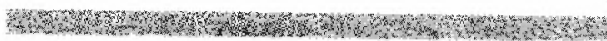

O problema é que operador e usuário não têm liberdade de definir, caso a caso, de quantos trabalhadores necessita. Este número é fixado por tabela, o que elimina importante fonte de racionalização do custo do trabalhador portuário, minando, na prática, os ganhos obtidos mesmo nos portos em que o OGMO já está mais atuante.

Esse problema é resultado do número excessivo de trabalhadores que se encontra no porto. Isso justificou o fato de a Lei 8.630/93 conter um dispositivo aparentemente contrário à concorrência: reduzir a oferta de mão-deobra nos portos, estimulando o cancelamento dos registros pelos portuários avulsos por meio de pagamento de indenizações (o PDV portuário) conforme Artigo 59.14, 15

Sendo os portuários avulsos - em última análise, mão-de-obra terceirizada para trabalho sem uma base regular -, caberia indagar por que a concorrência da mão-de-obra não poderia se dar individualmente ou por cooperativas. Nesse espírito, não faria sentido regis-
11. Observe-se que já houve forte demanda dos trabalhadores para unificar as negociações em nível nacional, o que eliminaria a concorrência interportos nesse quesito.

12. Apesar de haver alguma margem de flexibilidade para a concorrência intraporto. como acentuado por Lima \& Velasco e que será discutido adiante.

13. GEMPO (Grupo Executivo para Modernização dos Portos). Op. cit.

14. 0 GEMPO informa que já foram pagas cerca de 6.000 indenizações em todo 0 Brasil.

15. As virtudes da concorrência em termos de preços menores da mão-de-obra seriam, de fato, invariantes, no curto e médio prazos da implementação da Lei dos portos, à oferta global de trabalhadores portuáríos. 
tro de mão-de-obra a não ser aquele feito para fins de prover informação ao usuário sobre a qualificação e o treinamento do portuário individual e sem qualquer tipo de restrição à entrada.

No entanto, dadas as peculiaridades da força dos sindicatos portuários, o modelo baseado no OGMO parece ser a configuração mais razoável, pelo menos até o momento. Seria ilusório conceber um ambiente plenamente competitivo na oferta de mão-de-obra no porto, a partir de várias cooperativas ou mesmo individualmente, oferecendo serviços com menores preços e melhor qualidade. A não-consolidação do OGMO possivelmente implicaria a manutenção da força do sindicato, que continuaria atuando como uma "cooperativa única", havendo uma tendência natural a essa configuração monopolista. Ou seja, no presente momento, o fortalecimento do OGMO parece ser, no momento, o caminho mais adequado para melhorar a eficiência da mão-de-obra no porto a despeito de constituir uma agência única.

No futuro, as possibilidades de ampliar a lógica concorrencial no fornecimento da mãode-obra serão condicionadas pelos seguintes aspectos:

- o movimento de aposentadoria dos atuais avulsos;

- o crescimento das próprias exceções de contratação pelo OGMO, que incluem o incremento do número de terminais privativos e algumas possibilidades da Lei (exploradas abaixo) no item VI-b;

- a importância relativa de eventual convergência de interesses entre operadores portuários e sindicatos, o que caracterizaria uma simples substituição dos últimos pelos primeiros no monopólio da contratação;

- o papel do OGMO como redutor do custo de transação na contratação de mão-deobra. Afinal, um organismo coordenador que centralize a contratação de mão-deobra pode reduzir o custo de procura tanto para usuários como para os operadores portuários;

- a progressiva introdução da multifuncionalidade no trabalho portuário, buscando reduzir a segmentação das atividades portuárias (Ação e Projeto 4 do PIMOP), que deve proceder mudanças qualitativas importantes na forma de contratação de mãode-obra no porto, reduzindo o número de agentes envolvidos e, portanto, o custo, além de tornar a operação mais eficiente.

\section{Serviço de praticagem}

Os práticos configuram categoria à parte, não se sujeitando ao OGMO. Sua função consiste na manobra dos navios, conduzindo-os da entrada dos portos até os berços de atracação e vice-versa. Isso requer conhecimento aprofundado das características de navegação nas imediações do porto de forma a evitar acidentes.

Esse quesito de elevado conhecimento do local para garantir a segurança dos navios configura uma natural barreira à entrada de novos práticos e justifica a regulamentação deste serviço. Assim, o ingresso na profissão demanda rigoroso exame aplicado pela Marinha do Brasil e estágio de qualificação.

Segundo o CONAPRA (Conselho Nacional de Praticagem), como "os serviços de praticagem são, normalmente, pagos pelos armadores, [...] os custos dos serviços de praticagem não interferem na formação dos custos da logística de transbordo e de processamento de cargas", ou seja, "os custos dos serviços de praticagem interferem apenas na formação do frete marítimo e não na composição dos custos portuários".

No entanto, tal como em análises de incidência de imposto, um aumento do custo da praticagem deslocaria a curva de oferta dos armadores para cima. A incidência desse aumento seria distribuída pelos donos da carga e armadores. $O$ ônus relativo de cada um dependerá das elasticidades de demanda e oferta por serviços de frete marítimo. Supondo o caso extremo de uma demanda de mercado totalmente inelástica, todo o custo elevado da praticagem seria repassado pelo armador para o dono da carga. Assim, alguma parcela do ônus será transferida para o dono da carga, onerando o custo dos produtos. No limite (curva de demanda vertical), o ônus integral será arcado pelo dono da carga.

Argumenta-se frequientemente que o problema maior dos altos custos do serviço de praticagem reside na regulação que estabelece um número máximo de práticos por porto pela Marinha. No entanto, uma medida que apenas elimine essa restrição e gere aumento da oferta de práticos não é condição suficiente para ampliar a concorrência na oferta do serviço. Isso porque, se os práticos em cada porto se mantiverem sob o guarda-chuva de apenas uma associação, pode ocorrer que apenas o ganho por prático se reduza (pois mais práticos estariam 
ganhando o mesmo valor global), mas sem redução do custo para o armador e, por conseguinte, para o usuário. Pareceria recomendável, portanto, maior descentralização do serviço de praticagem em cada porto juntamente com o aumento da oferta de práticos. As duas medidas seriam complementares e deveriam ser empreendidas em conjunto.

\section{O processo concorrencial dos operadores portuários pode ser limitado, ademais, por razões estruturais.}

Uma medida complementar interessante seria permitir que as empresas de navegação e concessionárias de terminais privativos, dentre outros, tivessem seus próprios práticos, o que exigiria uma flexibilização maior do processo de seleção a cargo da Marinha, no sentido de ampliar o número de práticos. A Lei $9.537 / 97$, recentemente aprovada, que dispõe sobre a segurança do transporte aquaviário, aprovada na Câmara dos Deputados e já encaminhada ao Senado, procura oferecer uma solução. Destaquem-se alguns pontos importantes da Lei:

- o Parágrafo $3^{2}$ do Artigo 13 assegura a todo prático habilitado o livre exercício do serviço de praticagem, individualmente, organizado em associação ou contratado por empresa;

- o Parágrafo 4 do mesmo Artigo permite que a autoridade marítima habilite comandantes de navios de bandeira brasileira a conduzir a embarcação sob seu comando no interior de zona de praticagem especiffica ou em parte dela, os quais seriam considerados práticos nesta situação exclusiva.

Essas novas disposições legais são, em geral, positivas, pois permitem a ampliação da concorrência no serviço de praticagem. No entanto, há o risco de as mesmas tornarem-se inócuas do ponto de vista da concorrência, já que podem continuar sendo fixados o número de práticos necessário para cada zona de praticagem (Artigo 14, Parágrafo Único, Inciso I) e o preço do serviço (Inciso II).
Quanto ao primeiro aspecto, não parece apropriada uma regulação do número de práticos. Seria mais adequado tornar mais aberto o processo de habilitação, deixando ao mercado a determinação desse quantitativo, como ocorre com outras profissões que requerem qualificação.

Além disso, a regulação de preços deve ser uma exceção, aplicada apenas quando se constatar que não é possível haver concorrência no serviço de praticagem de um determinado porto. Ademais, os preços deveriam constituir tetos e não valores absolutos, sendo válidos apenas para os navios e empresas que não dispuserem de prático próprio (possibilidade que pode ser aberta por essa Lei). Assim, mesmo que as pré-condições de concorrência se estabeleçam no serviço de praticagem nos portos, a fixação de preços pela autoridade marítima pode simplesmente solapar as vantagens do mesmo. De qualquer maneira, para assegurar a devida aplicação das normas concorrenciais, caberia uma maior cooperação entre o CADE e a autoridade responsável no exercício dessa regulação.

Outras críticas devem ser efetuadas à nova Lei:

- é fundamental que os exames de qualificação sejam freqüentes e tenham apenas caráter eliminatório, ou seja, não deveria haver número determinado de vagas, pois esse é um serviço em que o mercado, e não um ente regulador, deve estabelecer a quantidade ofertada;

- não faz sentido, no Parágrafo $4^{2}$ do Artigo 13, a limitação da possibilidade de habilitação a prático apenas para comandantes de navios de bandeira brasileira. Cerca de 98\% das embarcações que entram nos portos brasileiros não possuem bandeira brasileira;

- o Inciso XV do Artigo $2^{2}$ define o prático como não-tripulante. Isso pode inviabilizar a habilitação do comandante do navio como prático, de acordo com o Parágrafo $4^{0}$ do Artigo 13, por ser o comandante também um tripulante. Assim, a expressão "não-tripulante" pode limitar o escopo do aumento da concorrência no serviço;

- os dois últimos dispositivos (obrigação de bandeira brasileira e não-tripulante) podem reduzir muito, na prática, os ganhos almejados com o Parágrafo 4o do Artigo 13. É razoável postular, entretanto, que parte 
desses problemas possa ser sanada através da necessária regulamentação dessa legislação que ainda está por vir.

\section{Flexibilidade da contratação de trabalhadores em terminais privativos}

O Artigo 56 da Lei 8.630/93 faculta aos concessionários de terminais privativos a contratação de trabalhadores por prazo indeterminado, observado o disposto no contrato, convenção ou acordo coletivo de trabalho nas respectivas categorias econômicas preponderantes, devendo estas manter a atual proporção entre trabalhadores com vínculo empregatício e trabalhadores avulsos.

No caso de líquidos a granel, por exemplo, há independência dos terminais privativos não só em relação à mão-de-obra, mas também a toda a estrutura de funcionamento do porto organizado, incluindo armazenagem e todo o serviço de movimentação de cargas. ${ }^{16}$ A dependência dos granéis sólidos e, principalmente, da carga geral em relação ao cais público é maior.

Observe-se que, mesmo para os terminais privativos, há restrições para a contratação de mão-de-obra, tendo em vista a obrigatoriedade da proporção trabalhadores com vínculo empregatício/avulsos. Apesar disso, ainda constitui um regime de contratação mais flexível do que para o resto do porto. ${ }^{17}$

\section{TERMINAIS PRIVATIVOS}

\section{Terminais privativos e cargas de terceiros}

O Inciso II do Parágrafo $2^{a}$ do Artigo $4^{a}$ da 16. A FIPE (1996) contém um dado curioso. No caso da Petrobrás, apesar de a empresa realizar toda a operação de embarque e desembarque em seu terminal marítimo com pessoal próprio, a CODESP cobra não apenas pelo transporte por dutos, como também pela capatazia. 0 mesmo problema fol observado para produtos quimicos em geral.

17. Em Santos, por exemplo, há cinco terminais privativos: Cosipa, Ultrafértil, Cutrale, Dow Quimica e Cargill.

18. Por exemplo, seria o caso de algumas poucas empresas de navegação se verticalizarem na operação dos terminais e bloquearem, colusivamente, 0 acesso das concorrentes, especialmente as de linhas não-conferenciadas. Estas últimas, como será visto na seçāo VIII, cumprem um papel de destaque na concorrência da navegação. ser grandes, apesar de ser justamente nessas cargas que o seu terminal deve ser mais especializado. Ou seja, não é claro se a abertura dos terminais privativos será uma medida de tão largo alcance, apesar de meritória. Cabe também avaliar até que ponto a carga geral, normalmente transportada pelos portos públicos, terá ganhos de custo ao efetuar movimentações pelos terminais privativos, normalmente mais especializados.

\section{CONCESSÃO DE TERMINAIS PRIVATIVOS E CONCORRÊNCIA}

A concessão de terminais pode ter implicações relativas a concorrência. Isso é verdadeiro especialmente para terminais privativos, em que há elevado grau de especialização por tipo de carga.

Imagine-se, por exemplo, que o ganhador da concessão de um terminal especializado em Santos seja um grupo que atue verticalizado tanto nos mercados de insumo upstream como nos de produto downstream. Imagine-se que, apesar de esse grupo ser responsável por toda a produção nacional desse insumo, esse mercado upstream é altamente contestável via importações. No entanto, suponha-se que a única porta de entrada de importações de insumos seja aquele terminal especializado, cujo concessionário passa a ser aquele grupo. Nesse contexto, a privatização poderia gerar problemas de acesso das empresas no mercado downstream aos insumos importados, dado que a porta de entrada é controlada por concorrente.

Mesmo a concessão de terminais de carga geral pode suscitar problemas caso se verifique um reduzido número de concessionários que viabilize práticas colusivas. Tais comportamentos podem gerar inclusive o bloqueio ao acesso de eventuais concorrentes dos concessionários nos mercados de produto ou mesmo de transporte. ${ }^{18}$

Nesse sentido, é importante avaliar como é abordada a questão concorrencial nos contratos de concessão de terminais. Em um contrato de concessão firmado para o arrendamento de área de $100 \mathrm{mil} \mathrm{m}^{2}$ no porto de Santos, as principais cláusulas relacionadas à questão concorrencial foram as seguintes:

1. Cláusula 52.1: Define que só pode haver um vencedor para a licitação de cada um dos seguintes três terminais no Porto de Santos: PROAPS 13,19 e 23. Esse é um dis- 
positivo importante para a concorrência, pois evita concentração de propriedade de terminais. Por outro lado, não há como inferir essa restrição em relação a outros terminais e nem se as áreas arrendadas são grandes o suficiente para justificar mais de um terminal, o que se configura em informações muito específicas. É importante destacar, de qualquer forma, que há certa economia de escala no tamanho das áreas de cada terminal, que dependerá da especialização específica de cada um (fertilizantes, aço, automóveis, suco de laranja etc.). Assim, seria muito difícil avaliar o tamanho ideal de cada terminal a ser concedido, dado o trade-off entre a maximização do processo concorrencial, considerando uma escala mínima eficiente relacionada ao tamanho da área concedida para cada tipo de terminal. Além disso, não se aprofunda o que se entende por "vencedor". Não esclarece se é qualquer empresa de um consórcio vencedor ou empresa que detenha mais que determinada participação no consórcio vencedor.

2. Cláusula 6.6: Determina que o controle societário da concessionária só poderá ser modificado após prévia anuência da CODESP. Pode ser um instrumento para evitar concentração da propriedade de terminais, para o que a cooperação com o CADE é importante.

3. Cláusula 6.7: Veda participação isolada na licitação de empresa estrangeira. Tal veto pareceria inadequado ao restringir a possibilidade de empresas estrangeiras aumentarem sua capacidade de importar e exportar.

4. Cláusula 100.2: Determina a apresentação pela licitante de Proposta de Metodologia de Execução, com planos de investimento, perspectivas mercadológicas e ainda análise de mercado sobre concorrência intraporto e entre os portos. Constitui uma idéia interessante, mas caberia concretizar os instrumentos de tal análise.

\section{EMPRESAS DE NAVEGAÇÃO E CONCORRÊNCIA}

Conforme Lima \& Velasco, ${ }^{19}$ as empresas de navegação atuam cartelizadamente no plano internacional, impondo fretes segundo suas estratégias empresariais, especialmente em países não-desenvolvidos. ${ }^{20}$
Segundo a FIPE, ${ }^{21}$ exportadores e importadores contam com os serviços de linhas marítimas regulares e não-regulares (eventualtramp). Em relação às primeiras, que apresentam trajetos fixos, o importante é a diferenciação entre as linhas conferenciadas e as nãoconferenciadas (outsiders). As conferências de linhas são acordos tarifários estabelecidos entre os armadores que operam uma mesma rota. Conforme o estudo, "as conferências de linha são tentativas de se eliminar a concorrência na navegação marítima, ou seja, as empresas procuram, através de acordos, determinar preços independentemente do estado da deman$d a "$.

\section{O dispositivo da pré- qualificação, apesar de constituir uma possível barreira à entrada burocrática, pode apresentar também uma justificativa do ponto de vista da eficiência que deve ser ponderada.}

\section{Nand}

Esse poder de ação cartelizada das empresas de navegação foi reduzido, de acordo com o estudo, tendo em vista o aumento da oferta de embarcações, a maior capacidade das recém-construídas e o fluxo de novos armadores estrangeiros em portos brasileiros. Esse fato aumentou a concorrência, permitindo a quebra de várias regulamentações existentes e a redução do poder de regulação do valor do frete marítimo das conferências. Segundo o estudo, "os serviços regulares de linha não conferenciados - outsiders - são serviços oferecidos por armadores independentes que cobram tarifas mais baixas para poder concorrer com os armadores conferenciados". Nesse contexto, o chamado special contract tem assumido importância crescente em relação às conferências marítimas.

Para ilustrar esse aumento da contestabilidade do mercado de transporte
19. LIMA, E. T., VELASCO, L. M. Op. cit

20. De acordo com estudo da UNCTAD, citado por Lima \& Velasco, os fretes foram até $100 \%$ superiores aos praticados nos países desenvolvidos. Sendo um cartel que age coordenadamente em nivel internacional, constituindo um mercado geográfico mundial relevante, fica, no entanto, sem explicaçăo essa diferenciação de preços entre norte e sul, a não ser que se presuma a diferenciação das elasticidades de demanda entre as duas regiōes.

21. FIPE. Op. cit. 
marítimo, vale citar o evento descrito pela FIPE, no qual, no segundo semestre de 1994, os armadores no mercado liner terms procuraram estabelecer uma sobretaxa sobre o frete marítimo para os portos do Rio de Janeiro e de Santos devido aos problemas de congestionamento destes últimos. A medida obteve o apoio de três conferências marítimas - Mediterrâneo, Europa e Interamericana. Conforme o estudo, "as dificuldades de sustentar esta medida em face da grande concorrência por fretes terminaram por derrubar a sobretaxa". Essa constatação seria especialmente verdadeira para o caso de granéis sólidos e líquidos, em que, ainda segundo a FIPE, 22 "predomina uma concorrência desenfreada na navegação", e no qual o armador não paga as despesas de embarque e desembarque. ${ }^{23}$

\section{A autarquia deve ter um papel de grande relevância na implementação da Lei dos portos em seus aspectos concorrenciais.}

\section{Hather}

Por outro lado, mesmo com essa concorrência crescente, ainda remanesce um poder de mercado das empresas conferenciadas que acabam por servir de parâmetro efetivo para as tarifas praticadas. Há duas razões para isso. Primeiro, mesmo tendo aumentado a oferta de serviços de transporte marítimo, aumentou muito a demanda pelos mesmos com o incremento do fluxo de comércio recente. Segundo, a segurança do serviço prestado pelas linhas conferenciadas é, em média, maior.

\section{CUSTO PORTUÁRIO E CONCORRÊNCIA}

22. Idem, ibidem.

23. Não é claro se o poder de barganha dos armadores em carga geral é maior por causa do liner term (um contrato que talvez seja aceito pelo usuário por critérios de eficiência) ou se essa modalidade imposta justamente por causa do elevado poder de barganha da armação nesse segmento. Possivelmente um fortalece 0 outro. exemplo, uma série de custos são repassados de um agente para o outro até, finalmente, chegar ao usuário. Essa teia de relações apresenta implicações do ponto de vista da estratégia para se tratar a questão concorrencial intraporto, ilustrada na Figura 1.

De acordo com a Figura 1, se não houver concorrência entre os operadores portuários, todo o esforço de modernização das relações capital-trabalho via OGMO pode ficar prejudicado no sentido de reduzir o custo da operação. Afinal, o usuário paga diretamente ao operador que negocia com o trabalhador. O operador repassará tanto mais para o usuário a redução do custo da mão-de-obra, quanto mais o mesmo operar em um ambiente concorrencial. Pode-se imaginar uma situação-limite na qual um operador com elevado poder de mercado no porto, pela falta de concorrência, venha a absorver todo o ganho da racionalização da contratação da mão-de-obra portuária sem repassá-lo para o usuário.

Também no caso da praticagem, é evidente que todo o esforço de racionalização da oferta desse tipo de serviços demanda a existência de efetiva concorrência entre as empresas de navegação. No limite, a ampliação da concorrência no serviço de praticagem poderia ter efeitos pequenos na redução do custo para o usuário se a redução de custo gerada for absorvida apenas pelas empresas de navegação. $O$ mesmo vale para a racionalização dos serviços prestados pelas CIAs Docas. Observe-se que, mesmo aumentando a eficiência na administração portuária, o repasse dos benefícios ao usuário final pode ser limitado apenas à taxa de armazenagem (item 2 do diagrama), pois as taxas de infraestrutura, serviços gerais e aluguel de equipamentos (itens 4, 5 e 6) passam pelo operador portuário, que, se estiver fora de um ambiente concorrencial, pode absorver todo o benefício.

Cabe, no entanto, destacar que esse diagrama é bastante simplificado e não cobre todas as possíveis modalidades de relações entre os agentes do porto. Conforme a FIPE (1996), os contratos realizados para transporte de cargas marítimas obedecem a padrões definidos no INCOTERMS (International Commercial Terms), elaborado pela Câmara de Comércio Internacional. Há vários tipos de contratos consistentes com o INCOTERMS usualmente adotados na navegação marítima e negociados entre exportadores e importadores.

Para demonstrar como o diagrama acima pode ser modificado e suas implicações para a 
Figura 1 - Sistema de pagamentos no porto de Santos

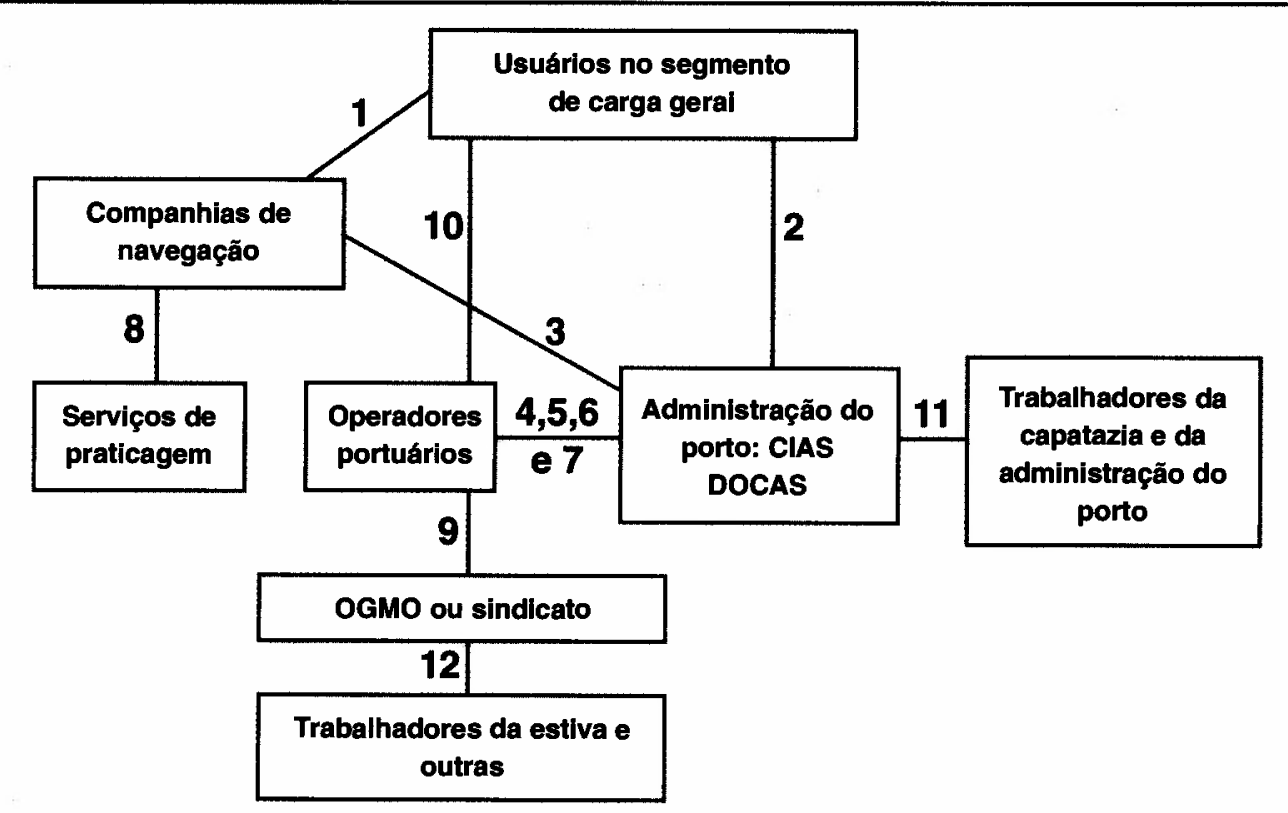

1. Frete.

2. Taxa de armazenagem: inclui recebimento, abertura para conferência aduaneira, arrumação e serviços correlatos, recondicionamento e pesagem. Em alguns casos, a armazenagem é feita em terminais retroportuários que não são de propriedade das CIAs Docas. ${ }^{24}$

3. Taxa de utilização da infra-estrutura portuária: remuneram as obrigações consignadas à administração do porto, a utilização das infra-estruturas de acesso aquaviárlo, de acostagem e da faixa do cals por ela mantidas.

4. Taxa de infra-estrutura operacional.

5. Aluguel de equipamento da administração do porto.

6. Taxa de serviços gerais: inclui água, energia elétrica e transporte executado pela administração do porto.

7. Pagamento do serviço de capatazia: em longo prazo, esse pagamento deve entrar na relação usuário-operador em 10.25

8. Taxa do serviço de praticagem (prátlcos não abrangidos pelo OGMO e nem pelo sindicato de portuários, apresentando organização própria).

9. Remuneração definida em negoclaçăo coletiva entre operadores e sindicatos do serviço de estlva (em longo prazo, o espírito da Lei é incluir também a capatazia fora das CIAs Docas).

10. Pagamento do servlço de operação portuária.

11. Pagamento aos trabalhadores da capatazia e administração portuárla.

12. Pagamento da estlva e outras categorlas.

Fontes: FIPE e GEMPO. Elaboração dos autores.

concorrência, considerem-se os contratos liner terms. Neles, os custos associados às operações de embarque no porto de origem, estiva, transporte marítimo, desestiva e desembarque estão incluídos no valor do frete. Ou seja, parte da (ou toda a) relação dos usuários com os operadores portuários (item 10) está na relação dos usuários com os armadores ${ }^{26}$ (item 1). Desta forma, são as CIAs de navegação que contratam com os operadores portuários (ou até diretamente com os sindicatos) várias das operações, e não os usuários diretamente. Os principais usuários desse tipo de contrato são as cargas gerais em conteiners, preponderantemente produtos industrializados e semi-in dustrializados. Observe-se que os problemas de concorrência supracitados são magnificados. Nesse tipo de contrato, podem existir dois intermediários (armadores e operadores) que irão absorver as eventuais redu-
24. Neste último caso, estudo da FIPE (p.97) revela que o custo desses armazéns está entre os mais pesados em Santos, havendo um número insuficiente, sendo sua concessão determinada por fatores políticos, criando barreiras a entradas indesejáveis.

25. Em longo prazo, pretende-se unifica capatazia e estiva em um só processo, racionalizando a movimentação de cargas. o PIMOP contempla esse projeto implantando a multifuncionalidade no trabalho portuário.

26. Há certa preocupação com a proliferação excessiva de operadores portuários, tendo em vista que há exigências de capital mínimo para uma operaçāo eficiente, muitas vezes nāo preenchidas. Se houvesse concorrência adequada nesse setor, obviamente os menos eficientes seriam eliminados. No entanto, a questão da baixa eficiência não parece estar sendo resolvida naturalmente pelo mercado (nesse caso, nem se exigiriam regras de pré-qualificação). Segundo algumas opiniões nãoconfirmadas, isso pode estar ocorrendo por dois fatores conjugados que se tornam, conjuntamente, condiçōes suficientes para viabilizar a ineficiência: (a) vários operadores portuários são testas-de-ferro dos armadores e (b) não há concorrência no setor de navegação. Ou seja, não havendo concorrência no transporte maritimo e sendo o operador portuário uma mera extensão do armador, esse último pode se dar ao luxo de ser ineficiente na operação. 
ções de custo com a resolução dos problemas de mão-de-obra com o OGMO.

Em outra modalidade, como o free in and out (FIO), o frete inclui apenas o transporte marítimo, o que é mais fiel ao diagrama acima, incluindo cereais, minério, trigo e granéis líquidos embarcados através de dutos.

A configuração de mercado de outros agentes intervenientes entre 0 usuário-produtor $e$ as operações portuárias também podem ser importantes, como as tradings, que adquirem commodities agrícolas no local de produção e se encarregam de toda a logística de exportação, e os brokers (empresas especializadas em logística, normalmente utilizadas no comércio exterior de pequenas empresas).

\section{CONCLUSÕES}

A discussão anterior sugere pontos para incrementar o ambiente concorrencial no setor, tendo como base as Leis 8.630/93 e 8.884/94:

1. Avaliar se as normas exaradas pelos CAPs em cada porto e sua implementação pelas CIAs Docas têm restringido ou não a préqualificação de operadores portuários.

2. Avaliar se os operadores portuários estão sendo muito flexíveis nas negociações com o sindicato, dada sua capacidade de repassar custos mais altos de mão-de-obra para o usuário.

3. Eliminar a compulsoriedade de toda e qualquer tabela de turnos de trabalho tanto para os operadores como para os usuários.

4. Acelerar a implantação da multifuncionalidade do processo de trabalho portuário.

5. Avaliar a possibilidade de transferência da regulação do serviço de praticagem da autoridade marítima para a administração do porto.

6. Eliminar dessa regulação qualquer item referente a preços dos serviços quando em um determinado porto houver satisfatória concorrência na praticagem.

7. Eliminar restrições do número de práticos por porto, limitando-se a barreira à entrada ao processo de qualificação e certificação, que deve ser conduzido por entidade ligada ou à administração do porto ou ao CAP.

8. Eliminar restrições para que comandantes de navios possam ser práticos, respeitadas as normais atuais de número mínimo de manobras por período de tempo.

9. Eliminar restrições para que empresas concessionárias de terminais privativos possam ter seus próprios práticos, também respeitadas as normas supracitadas.

10. Eliminar restrição de existência de apenas uma associação na praticagem.

11. Facultar o exercício da profissão de prático independentemente de filiação a qualquer associação.

12. Avaliar a existência de conduta concertada dos armadores e a influência das linhas nãoconferenciadas nos preços dos fretes marítimos.

13. Promover a utilização de cláusulas concorrenciais nos editais de licitação de terminais. Exemplos destas últimas são as que impedem o controle de mais de um terminal no modelo estudado de Santos e as que determinam o não-bloqueio da movimentação de cargas de concorrentes em terminais especializados (suco de laranja, fertilizantes).

14. Evitar o uso de restrições a empresas estrangeiras nas licitações de terminais privativos.

15. Avaliar se as CIAs Docas utilizam, efetivamente, uma ótica concorrencial para controlar mudanças no controle acionário dos licitantes e para ponderar os dados sobre concorrência intraporto e entre portos fornecidos pelas licitantes.

16. Punir as eventuais infrações à ordem econômica verificadas no porto pelos dispositivos da Lei 8.884/94, sinalizando, de forma clara e inequívoca, aos agentes econômicos do porto que o CADE não tolerará abusos que estejam na órbita de sua competência.

Vale destacar especialmente esta última recomendação, que está diretamente relacionada ao trabalho do CADE. A autarquia deve ter um papel de grande relevância na implementação da Lei dos portos em seus aspectos concorrenciais, dos quais não pode se furtar. Nesse sentido, cumpre ressaltar que o CADE deve utilizar todos os instrumentos disponíveis na Lei $8.884 / 94$, inclusive os de caráter repressor, para restaurar, ou mesmo promover, o ambiente concorrencial no porto quando evidenciada infração. Ou seja, no âmbito da legislação existente (tanto a Lei 8.630/93 como a 8.884/94), cabe complementar a ação do GEMPO e dos Ministérios diretamente relacionados com a matéria, de forma a articular a defesa da concorrência com o propósito maior de modernização do sistema portuário e redução do Custo Brasil. 